\title{
Finalistas da Edição de 2011 das “Olimpíadas de Química"
}

Os finalistas das "Olimpíadas de

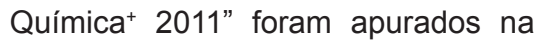
competição que decorreu em Aveiro, Porto e Lisboa no passado dia 12 de Março.

Integrada na celebração do Ano Internacional da Química, esta edição de 2011 voltou a registar um significativo aumento de escolas participantes, tendo sido a mais participada de sempre, com 159 Escolas inscritas, superando largamente os números dos anos anteriores (ver Gráfico).

A acolher estes participantes estiveram as equipas coordenadas pela Prof. Diana Pinto (Semifinal de Aveiro), Prof. Jorge Gonçalves (Semifinal do Porto) e Prof. Jorge Morgado (Semifinal de Lisboa). A todos os que contribuíram para o sucesso desta iniciativa a Direcção da SPQ expressa o seu agradecimento.

Os 27 alunos apurados disputaram a Final nacional, realizada no Departamento de Química da Universidade de Aveiro, a 7 de Maio, numa competição individual que incluiu uma prova teórica e uma prova prática laboratorial.

\section{Paulo Ribeiro Claro (pclaro@dq.ua.pt) Coordenador das Olimpíadas de} Química

\section{Lista dos Vencedores}

Semifinal de Aveiro (Departamento de Química, Universidade de Aveiro)

\section{Medalhas de Ouro}

ES/3B Soares Basto - Oliv.Azeméis

Prof. Responsável: Paula Ornelas

Catarina da Cunha Martins Costa

Diogo Nóbrega Catelas

João Paulo Martins Rosa

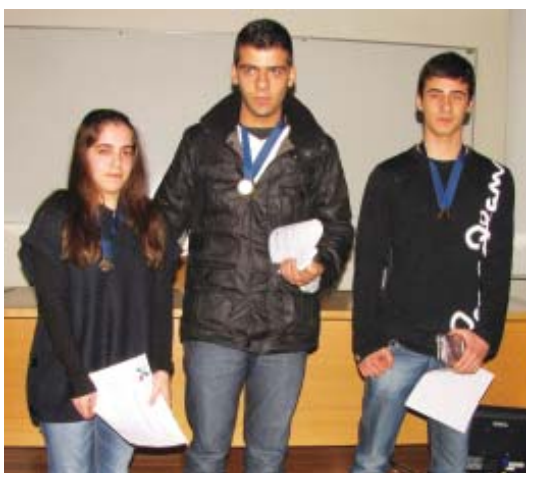

Número de Escolas inscritas nas Olimpíadas de Química+

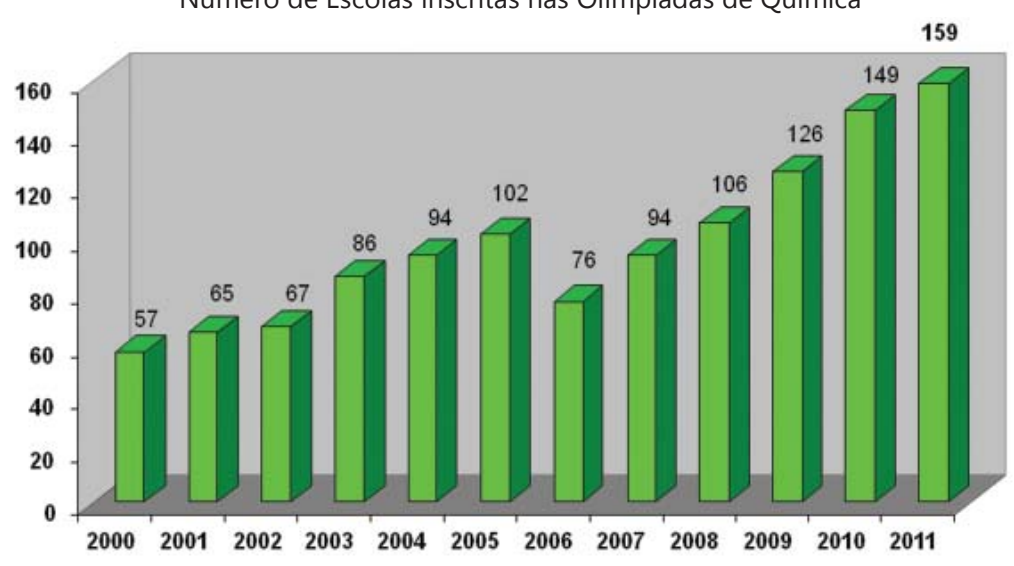

Medalhas de Prata

ES/3B de Vouzela

Prof. Responsável: Carlos Guerra

Ana Carina Gomes Ferreira

Daniel Filipe Rocha Figueiredo

Isabel Maria da Costa Monteiro

\section{Medalhas de Bronze}

ES Infanta D. Maria - Coimbra

Prof. Responsável: Ma Laura Nunes

Carlos Barbosa

Carolina Gonçalves

Francisco Machado

Semifinal do Porto (Departamento de QuímicA, Universidade do PoRTo)

\section{Medalhas de Ouro}

ES/3B Emídio Garcia - Bragança

Prof. Responsável: Teresa Calvo Pinto

Ricardo Rodrigues

Telma Moreno

Joana Piloto

\section{Medalhas de Prata}

Colégio de S. Gonçalo de Amarante Prof. Responsável: Ma Graça Costa Ana Rita Ribeiro Neves Mafalda Inês R. Freitas Gonçalves Marco Emanuel Castro e Silva

\section{Medalhas de Bronze}

ES/3B Carolina Michaelis - Porto Prof. Responsável: Ana Paula Santos João Paulo Pereira Rocha João Carlos Barbosa Oliveira Rui Miguel Almeida Alves

Semifinal de Lisboa (Instituto SupeRIOR TÉCNICO, UNIVERSIDADE DE LISBOA)

\section{Medalhas de Ouro}

ES/3B de D. Inês de Castro - Alcobaça Prof. Responsável: Gaspar Vaz

Bárbara Laczkovits

Catarina Correia

João Pereira

\section{Medalhas de Prata}

ES de Gago Coutinho - Alverca

Prof. Responsável: Mª Eugénia Pinto Catarina Soares

Hugo Cadilha

Rodrigo Capeleiro

\section{Medalhas de Bronze}

Colégio Salesiano Oficinas de S. José - Lisboa

Prof. Responsável: Teresa Paiva

Ana Rita Jorge Reis

Ricardo Miguel Cordeiro dos Santos

Tomás Martins de Oliveira Reis

\section{Fotografias das equipas vencedoras nas Semifinais das Olimpíadas de Química+ 2011 (da esquerda para a direita: Aveiro, Porto e Lisboa)}

